\title{
Senate slashes NASA's moon rock research...
}

IN a move which has sent shock waves through the US geoscience community, the Senate has decided to cut from the 1979 budget of the National Aeronautics and Space Administration all $\$ 5.7$ million requested for continuing research on rock samples brought back by the Apollo moon missions. The decision, which one lunar scientist described last week as a "bolt out of the blue", and another as a "major catastrophe for the whole international research community", was made on the recommendation of an appropriations subcommittee chaired by Senator William Proxmire, widely-known for his attacks on esoteric-sounding research.

Ninety-six separate groups in universities and research institutes throughout the country are working on projects under NASA's lunar sampling analysis programme; many now face the prospect of research funds drying up from 1 February next year.

The Senate appropriations committee directed that responsibility for funding such research should be passed to the National Science Foundation. The NSF, however, is concerned that a sudden influx of high-quality applications could strain its whole earth sciences programme. The $\$ 24.5$ million budget for this programme is to be kept constant from the current year, and has not been increased by the committee to take account of the new demands.

Research on the large number of lunar samples brought back by various Apollo missions since the first moon landing in 1969 has already yielded substantial information not only about the structure of the moon itself, but also about the history of other planets, for example through analysis of past radiation and particle bombardment.

Despite occasional signals from the appropriations committee in the past that basic research of this type should not be the responsibility of NASA, funds for lunar sample analysis have remained roughly constant over the past few years, and the programme has received praise for the high quality of the science conducted.

The first indication that there might be trouble with the 1979 budget request came during the subcommittee's hearings. Responding to statements about the importance of the moon rocks from Dr Robert Frosch, administrator of NASA, and Dr Noel Hinners, associate administrator for space science, $\mathrm{Mr}$ Proxmire quipped that if the rocks were so valuable, perhaps scientists should pay for the privilege of studying them. Mr Proxmire's subcommittee subsequently cut the full request for \$5.7 million for lunar sample analysis from the agency's 1979 budget, a move
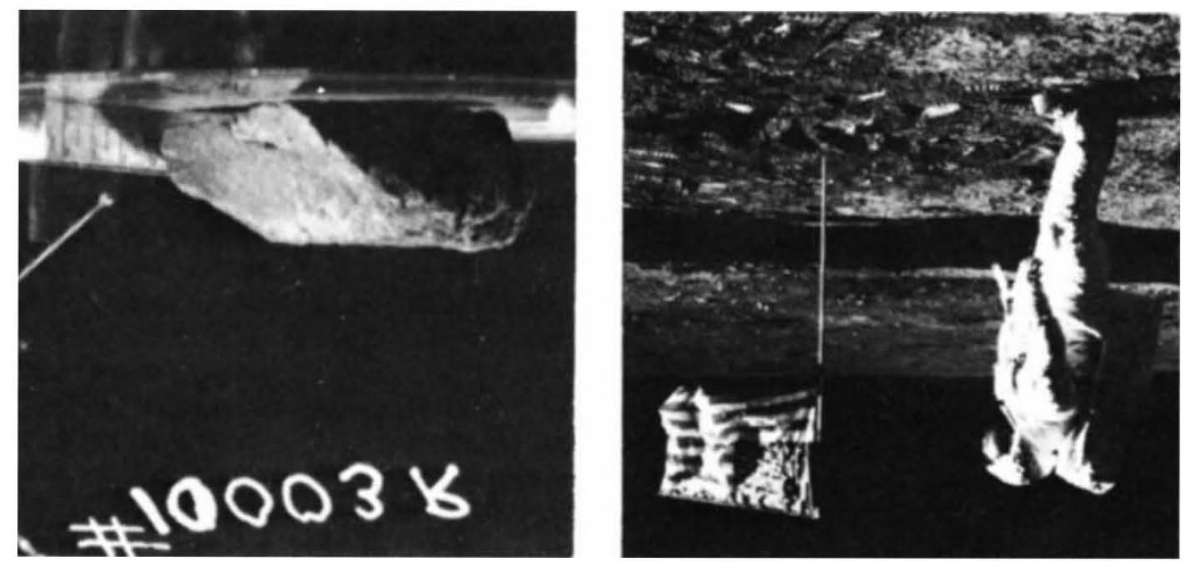

Above: moon rock sample. Right: its collector, astronaut Aldrin. Will research now have to stop?

that, despite frantic moves by scientists to have at least part of the funds restored, was approved by the full committee at the beginning of last week.

In its report to the Senate on the bill appropriating the NASA budget, the committee said that in cutting the NASA funds, it expected the NSF to accept applications for such research. The committee added that NASA could continue to support, from other available funds, "the more promising on-going lunar sample analysis on a short-term basis while new funding mechanisms, in cooperation with NSF, are established".

Under a separate section of the bill appropriating funds to the NSF, the committee directed that proposals for lunar sample analysis "are to be evaluated competitively with other applications for funds for basic research in the geological sciences".

The lunar sample research is not the only project to have suffered at the hands of the appropriations subcommittee. The committee also deleted all funds for research into extraterrestrial life forms, a previous recipient of $\mathrm{Mr}$ Proxmire's "Golden Fleece" award, whose budget had already been reduced from $\$ 2$ million to $\$ 600,000$ by the House appropriations committee.

But it is the moon rock decision which is likely to have the greatest impact on the scientific community. Of particular concern to NSF is that many of the projects now funded by NASA would come under the geochemistry budget which has already been held down to under $\$ 8$ million, and can at present fund less than half the proposals it receives. An influx of new, high quality applications, could prove devastating to current programmes and new proposals alike.

"One serious consequence could be on scientific cooperation. In the past, people from different disciplines have been able to support each other when good projects have been proposed by NASA; but the pressures to be more aggressive will become quite severe, for example possibly between those engaged in terrestrial and extra-terrestrial research", said one member of the lunar and planetary laboratory at Arizona State University.

"The outcome of this decision will be to devastate a whole area of research, not only in the US, but in the rest of the world as well", says Dr Gerry Wasserberg, professor of geology and geophysics at California Institute of Technology. "It will be a major blow to the whole space science programme, as well as to the world-wide study of extra-terrestrial materials".

Despite objections from, among others, Senator Harrison Schmitt, one of the original Apollo astronauts who described the cuts as "incredibly unbelievable", they were left standing by the Senate when it considered the appropriations on Monday. The main hope now is that at least some of the money can be restored at the conference stage, when some lively horsetrading is expected beween House and Senate. The Senate appropriations committee, for example, disagreed with its House counterpart that $\$ 30$ million should be put aside from the budgets for the solar polar mission, the space telescope and the Jupiter orbiter probe to cover possible cost over-runs in the space shuttle programme.

Scientists are therefore hoping that, in return for a compromise agreement on these actions, the Senate committee will be prepared to reinstate some of the money for the lunar sample analysis, for which the full $\$ 5.7$ million request was both authorised and appropriated by the House, Senator Proxmire has said that he might be prepared to accept a figure of $\$ 2.5$ million for the programme. But even this would have a serious impact on current research.

David Dickson 